\title{
O PENSAMENTO AMBIENTAL SISTÊMICO: UMA ANÁLISE DAS PESQUISAS DESENVOLVIDAS PELA ESALQ/USP
}

\section{THE SYSTEMIC ENVIRONMENTAL THOUGHT: AN ANALYSIS OF RESEARCH DEVELOPED BY ESALQ/USP}

\section{Renata Coelho Sartori ${ }^{1}$}

${ }^{1}$ Jornalista pela Universidade Metodista de Piracicaba, Especialista em Arte, Educação e Comunicação pela Faculdade Paulista de Artes, Doutoranda do Programa de Ciências Sociais da Universidade Federal do Rio Grande do Norte. Pesquisadora do Grupo de Estudos da Complexidade - GRECOM/UFRN - e-mail:

rcsartori@bol.com.br

\section{RESUMO}

Durante o século XX sedimentou-se a percepção de que o conhecimento disciplinar fragmentado é incapaz de explicar e resolver a problemática ambiental. A partir disso, surgiu um grande desafio no campo da educação: um amplo e complexo processo de reorientação do conhecimento, das ideologias, dos paradigmas científicos e das práticas de pesquisa. As questões ambientais e sociais abriram o caminho para o pensamento sistêmico e também para métodos interdisciplinares de pesquisa. Este artigo é parte de uma pesquisa que analisou as teses de livre-docência desenvolvidas na Escola Superior de Agricultura "Luiz de Queiroz" da Universidade de São Paulo, Campus Piracicaba, SP (ESALQ/USP) no período de 1998 a 2002, procurando revelar a presença ou não do novo paradigma científico, através da análise das abordagens adotadas em relação às questões ambientais em sua complexidade.

Palavras-Chave: Pensamento ambiental. Paradigmas científicos. Teses de livredocência. Comunicação científica. ESALQ.

\section{ABSTRACT}

In the 20th Century the perception that the fragmented disciplinary knowledge has been unable to explain and solve environmental problems consolidated. Since 
then, a major challenge has raised in the educational field: a wide and complex reorientation of process knowledge, ideologies, scientific paradigms and research practices. The environmental and social questions opened a path for systemic thought and interdisciplinary research methods, capable of linking different disciplines in order to understand multiple relations, causalities and interdependence among natural and social processes. This article is part of a research that analyzed the post-doctoral theses developed by the teaching staff at Escola Superior de Agricultura "Luiz de Queiroz", of São Paulo' University - Campus Piracicaba, SP ESALQ/USP, from 1998 to 2002, looking for to disclose the presence or not of the new scientific paradigm, through the analysis of the boardings adopted in relation to the environmental questions in its complexity.

Keywords: Environmental thought. Scientific paradigms. Post-doctoral theses. Scientific communication, ESALQ.

\section{INTRODUÇÃO}

O conhecimento científico necessário para compreender à dinâmica dos processos, socioambientais situa-se além do conhecimento disciplinar. Como destacado por Leff (2002), o saber ambiental não constitui um campo discursivo homogêneo para ser assimilado pelas diferentes disciplinas científicas. O saber ambiental emerge de uma razão crítica, configurando-se em contextos ecológicos, sociais e culturais. Segundo o autor, este saber se estende além do campo de articulação das ciências, para o terreno dos valores éticos, dos conhecimentos práticos e dos saberes tradicionais.

Dessa forma, os problemas da complexa rede de relações socioambientais necessitam de uma abordagem sistêmica e de métodos interdisciplinares de pesquisa, que não estão inseridos na ciência clássica, mas sim, em um novo paradigma, como afirma Morin:

Chamo paradigma de complexidade ao conjunto dos princípios de inteligibilidade que, ligados uns aos outros, poderiam determinar as condições de uma visão complexa do universo (físico, biológico, antropossocial) [...] O paradigma da complexidade não 'produz' nem 'determina' a inteligibilidade. [...] Incita a dar conta dos caracteres multidimensionais de toda realidade estudada (MORIN, 1996).

Na concepção de Kuhn, um paradigma é aquilo que os membros de uma comunidade partilham e, inversamente, uma comunidade científica consiste em homens que partilham um paradigma.

Segundo Kuhn (2000), a transição de um paradigma em crise para um novo, resulta em uma revolução científica. Um novo paradigma emerge antes que uma crise esteja "bem desenvolvida ou tenha sido explicitamente reconhecida" e para que tenha 
êxito, é necessário que "conquiste alguns adeptos iniciais, que o desenvolverão até o ponto em que argumentos objetivos possam ser produzidos e multiplicados".

A adoção de novos conceitos, diferentes enfoques e teorias originais serão decorrentes da implementação do eventual paradigma revolucionário.

O termo ruptura epistemológica deve-se a Gaston Bachelard. Segundo esse autor, "as crises de crescimento do pensamento implicam uma reorganização total do sistema do saber" (BACHELARD, 1999).

No contexto teórico em que estamos abordando a problemática ambiental, ou seja, da transição de um novo paradigma, é primordial que essa seja tratada na pesquisa de maneira complexa e interdisciplinar, buscando conhecimentos para padrões mais sustentáveis de desenvolvimento. Para tanto, como parte integrante desse processo, a universidade tem uma função significativa na produção e divulgação desses conhecimentos e o mesmo ocorre com as revistas e outras formas de comunicação científica, como as teses.

É importante ressaltar que as teses de livre-docência legitimam o saber desenvolvido pelas comunidades científicas e são consideradas as bases da pesquisa da Instituição (NOJIMOTO, 1996) e também, que as mudanças epistemológicas não só dependem do questionamento externo às ciências, mas das próprias estruturas do conhecimento em cada campo do saber, que as tornam mais flexíveis ou rígidas para incorporar e unificar o saber ambiental (LEFF, 2002). Tais colocações aproximam-se bastante da abordagem aqui analisada.

Portanto, a finalidade deste artigo é apresentar uma análise realizada sobre as pesquisas desenvolvidas pelas teses de livre-docência, da Escola Superior de Agricultura "Luiz de Queiroz", da Universidade de São Paulo (ESALQ/USP) Campus de Piracicaba/SP, procurando revelar a presença ou não do novo paradigma científico, a partir da análise das abordagens relacionadas às questões ambientais em sua complexidade e, em relação ao contexto interdisciplinar, tendo como interface suas dimensões sociais e culturais.

Buscou-se para a identificação do novo paradigma, os pressupostos de Edgar Morin sobre o Paradigma da Complexidade (pensamento sistêmico ou complexo ${ }^{1}$ ).

Ressalta-se que o relato deste artigo é fruto de numa pesquisa mais ampla na qual envolve a análise dos paradigmas utilizados nas pesquisas da ESALQ, disseminadas por dois periódicos científicos: um considerado o principal periódico da referida Instituição e o outro que é uma parceria do Instituto de Pesquisas e Estudos Florestais - IPEF com o Departamento de Ciências Florestais da ESALQ.

\footnotetext{
${ }^{1}$ Segundo Morin (2001) os dois termos pensamento sistêmico e pensamento complexo são sinônimos. Neste trabalho, optamos por utilizar o termo pensamento sistêmico e procuramos vincular este à temática ambiental. Na ciência do século XX, a perspectiva holística tornou-se conhecida como sistêmica, e a maneira de pensar que ela implica passou a ser conhecida como pensamento sistêmico. Os pioneiros deste pensamento foram os biólogos, que enfatizavam a concepção dos organismos vivos como totalidades integradas. Bertalanffy é reconhecido como o autor da primeira formulação de um arcabouço teórico abrangente com os princípios de organização dos sistemas vivos.

Na mudança do pensamento mecanicista para o pensamento sistêmico, a relação entre as partes e o todo foi invertida. No primeiro é considerado que em todo o sistema complexo o comportamento do todo pode ser analisado inteiramente a partir das propriedades de suas partes. No segundo mostra que os sistemas vivos não podem ser compreendidos por meio de análise. As propriedades das partes não são propriedades intrínsecas, mas podem ser entendidas dentro de um contexto do todo mais amplo.
} 
É importante destacar que não se pretende fazer uma crítica pessoal nem uma avaliação da produção científica dos pesquisadores da Instituição. Espera-se, contudo, que a pesquisa possa servir de reflexão sobre uma nova abordagem das pesquisas, sob um novo paradigma, sobre novas formas de pensar e produzir ciência, na comunidade acadêmica em geral e em particular na ESALQ.

Embora modesta, é relevante e recente porque partiu da análise de cinco anos de publicações desenvolvidas por pesquisadores da ESALQ, diante de mais de cem anos de existência da Instituição. Também não se pretende afirmar que toda a pesquisa da ESALQ encontra-se nas mesmas condições daquelas que aparecem nas teses de livre-docência. Ainda que se possa formular esta hipótese, ela deverá ser testada em outros trabalhos de investigação.

A hipótese da pesquisa assume que: as teses de livre-docência da ESALQ, consideradas como modelos de pesquisa da Instituição, não contemplam uma dimensão ambiental com pressupostos conceituais integrados, ou seja, a partir de uma visão sistêmica e interdisciplinar, tendendo à fragmentação e resultando na dificuldade em combinar aspectos ecológicos, sócio-econômicos, políticos e culturais. Assim, presumi-se que sejam pouco abordados assuntos envolvendo as questões sociais e culturais relativas à problemática ambiental.

\subsection{Justificativa do Trabalho}

A pesquisa justifica-se a partir da constatação de que o conhecimento científico moderno, especificamente dentro do contexto da complexidade da problemática ambiental, tem apresentado sinais de que está atravessando uma grande crise, o que vem a propiciar uma profunda reflexão epistemológica sobre o conhecimento científico. Os problemas emergentes do mundo moderno caracterizam-se por uma crescente complexidade, a questão ambiental, por exemplo, propõe a necessidade de um pensamento holístico (sistêmico), capaz de perceber as inter-relações entre os diferentes processos que incidem e caracterizam seu campo problemático.

Se as questões ambientais continuarem sendo abordadas de modo fragmentado e isoladas de um contexto sistêmico, a universidade tende a perder a capacidade de pensar os problemas concretos e emergentes, afastando-se assim, cada vez mais, da realidade que está em processo constante de mudanças.

Também é importante ressaltar que embora a extensa literatura sobre as questões ambientais tenha crescido consideravelmente durante os últimos anos, ainda há poucas publicações abordando a temática proposta por esta pesquisa, que utiliza a comunicação científica como relevante instrumento para análise da temática ambiental, propiciando a identificação do tipo de paradigma utilizado pelos pesquisadores de uma determinada comunidade científica.

A adoção de Edgar Morin como principal autor para a definição do novo paradigma deve-se ao fato de que ele pensa o sistêmico de uma maneira que já se tornou clássica. Seu pensamento não está tentando superar o pensamento sistêmico, como em vários autores contemporâneos. Por isso, considerou-se que Morin pode ser 
tratado como um autor que estabelece critérios bastante inclusivos em sua definição de novo paradigma, pois, não se teve à intenção de que as teses de livre-docência da Instituição fossem analisadas por um pensamento de vanguarda, mas por um pensamento moderado e fundado em avanços consolidados.

\subsection{A busca da Identificação de um Novo Paradigma através da Comunicação Científica}

Francis Bacon escreveu no século XVII sobre as duas principais razões pelas quais valeria a pena o homem conquistar novos conhecimentos: o que representa em si mesmo e as suas aplicações. Para ele, o aumento do conhecimento está "inextricavelmente ligado à sua comunicação, não exclusivamente com as gerações contemporâneas, mas também com as gerações subseqüentes" (MEADOWS, 1999).

Pelo fato de os problemas ambientais colocarem em xeque o modo de produção de uma sociedade, o modo de vida, os conhecimentos etc, o enfoque da pesquisa ambiental deveria redirecionar em profundidade o atual paradigma e estabelecer novos métodos para o conhecimento das questões ambientais, fazendo com que sejam fixadas as bases que deverão provocar mudanças e transformações nas pesquisas científicas e tecnológicas.

Nesse contexto, a comunicação científica pode ser considerada como um importante instrumento de análise na identificação dos paradigmas utilizados por pesquisadores de uma determinada comunidade científica.

A comunicação científica é definida por Garvey (1979) como:

A comunicação que incorpora as atividades associadas à produção, disseminação e uso da informação, desde o momento em que o cientista concebe uma idéia para pesquisar, até que a informação acerca dos resultados seja aceita como constituinte do conhecimento científico.

Segundo o autor, como conjunto de atividades que interferem na produção pode-se entender aquelas que contribuem para viabilizar um produto enquanto veículo (suporte físico) de comunicação do conhecimento. A comunicação científica é indispensável à atividade científica, pois permite somar os esforços individuais dos membros da comunidade científica. Eles trocam informações com seus pares, emitindo-as para seus sucessores.

Massarini e Moreira (1990) identificaram três linhas na comunicação científica: os discursos científicos primários (teses, periódicos, livros) - escritos por pesquisadores para pesquisadores (que foi a linha utilizada por esta pesquisa); didáticos (manuais científicos para ensino) e os da divulgação científica (revistas, jornais etc) - escrita por pesquisadores para o público em geral. Concluem que a ciência, sendo um empreendimento retórico, depende essencialmente da eficácia e da precisão das práticas de comunicação que adota. Cada discurso serve a um propósito determinado e busca atingir um público específico. 


\section{METODOLOGIA}

Foram analisadas:

- As teses de livre-docência defendidas pelos docentes da ESALQ no período de 1998 a 2002;

- Buscou-se conhecer as teses de livre-docência de 1998 a 2002, que tenham adotado uma abordagem sobre as questões ambientais dentro de um novo paradigma científico;

\subsection{A Coleta de Dados}

Em face aos objetivos da pesquisa, realizou-se a pesquisa documental na Biblioteca Central da ESALQ e documentos de bibliotecas digitais e virtuais que permitiram a realização do levantamento das teses de livre-docência, compreendidas no período de 1998 a 2002. A escolha desse período deveu-se ao fato de se considerar para análise as pesquisas mais recentes da Instituição.

Como objeto de análise, destacou-se a relevância da inclusão das teses de livredocência, pois de acordo com Nojimoto (1996) o autor considera esse tipo de tese como:

[...] reflexo da essência da pesquisa universitária por não possuírem orientações formais, são livres de restrições de temas, espaço, são desenvolvidas por pesquisadores com formação científica formal completa, são consideradas a base da pesquisa da Instituição e por fazerem parte da carreira universitária do pesquisador.

As teses de livre-docência, como o próprio nome diz, são realizadas por docentes que a partir da pesquisa realizada, legitimam o saber desenvolvido pela comunidade científica. Logo, as teses de livre-docência, sendo consideradas a base da pesquisa da Instituição onde são produzidas, constituem-se em indicadores adequados para a caracterização e o questionamento do tratamento que a mesma tem dado às questões ambientais.

\subsection{A Análise dos Dados}

Procurou-se, não identificar, as teses de livre-docência, pois a crítica não é pessoal. Para tanto, as mesmas foram citadas em códigos: Tese $\mathrm{n}^{\mathrm{o}} 1, \mathrm{n}^{\mathrm{o}} 2$, por exemplo, em vez da citação normal. Todavia, aos que se interessar em saber com exatidão o título da tese, uma relação poderá ser remetida. Para análise temática as teses foram quantificadas e categorizadas sob quatro aspectos: a) Caráter Interdisciplinar, b) Caráter Não-Interdisciplinar, c) Inserida no pensamento sistêmico e d) Não inserida no pensamento sistêmico. Todo o conteúdo de cada tese foi analisado a partir de uma leitura cuidadosa, buscando-se verificar a presença de um desses aspectos. 
2.3. Parâmetros de Análise para Caracterização da Pesquisa Interdisciplinar no Campo Ambiental

Para que as pesquisas fossem consideradas de caráter interdisciplinar adotou-se a necessidade da presença da inter-relação de duas ou mais disciplinas, conduzidas por profissionais de diferentes especialidades de conhecimento visando à convergência para uma determinada temática. Também se considerou como pesquisa interdisciplinar, as pesquisas acadêmicas que envolveram a comunidade tradicional (por exemplo: estudos etnobotânicos) com outras comunidades, além do segmento acadêmico.

2.4. Parâmetros de Análise para Caracterização da Pesquisa Inserida no Novo Paradigma (Pensamento Sistêmico)

Para que as pesquisas fossem consideradas como aliadas ao pensamento sistêmico, considerou-se aquelas que estivessem fundamentadas sob todos os setes aspectos que o compõem, considerou-se também o pensamento do contexto, pois tais aspectos estão interligados ao pensamento do contexto, de acordo com Morin.

Os sete aspectos abaixo se constituem numa síntese do pensamento sistêmico extraído de Morin e Kern (2002) Assim, a construção do pensamento sistêmico necessita de:

1- Um pensamento que ligue o que está separado e compartimentado, estabelecendo a relação entre a parte e o todo.

A complexidade sistêmica manifesta-se, sobretudo, no fato de que o todo possui qualidades e propriedades que não se encontram no nível das partes consideradas isoladas, e inversamente, no fato de que as partes possuem qualidades e propriedades que desaparecem sob o efeito das coações organizacionais do sistema (MORIN,1996).

2- Um pensamento radical, que vai à raiz dos problemas; a maioria dos problemas ambientais tem suas raízes em fatores sociais, econômicos e culturais;

3- Um pensamento multidimensional, não isolando uma parte do todo, assim como as partes umas das outras. A aspiração do pensamento à complexidade não quer todas as informações sobre o fenômeno estudado, mas busca respeitar suas diversas dimensões. O ser humano é ao mesmo tempo um ser biológico, psíquico, social, afetivo e racional;

4- Um pensamento organizador ou sistêmico que conceba a relação todopartes-todo, tal como nas Ciências Ecológicas e da Terra;

5- Um pensamento ecologizado que não isole o objeto de estudo, mas o considere em sua relação auto-eco-organizadora (trocas com o ambiente ou ecossistema), com seu ambiente - cultural, social, econômico, político, natural;

6- Um pensamento que conceba a ecologia da ação e a dialética da ação capazes de modificar ou anular a ação empreendida. "A ecologia da ação é, em suma, levar em consideração a complexidade que ela supõe, ou seja, o aleatório, o acaso, a 
iniciativa, a decisão, o inesperado, o imprevisto, a consciência de derivas e transformações" (MORIN, 2002b);

7- Reconhecimento de que o pensamento está inacabado e "dialoga" com a incerteza, sobretudo na ação, porque é próprio da ação operar com o incerto.

Ainda dentro do conceito de pensamento sistêmico coube definir o pensamento do contexto.

Conforme explica Morin (2002b) no pensamento do contexto devemos considerar que "O conhecimento das informações ou dos dados isolados é insuficiente. É preciso situar as informações e os dados em seu contexto para que adquiram sentido".

A hipótese do estudo foi verificada com base nas idéias de Edgar Morin. Certamente existem outros pensadores que poderiam compor esse universo, mas a escolha de Morin para nortear a linha de raciocínio da pesquisa foi intencional, uma vez que ele possui uma ampla trajetória intelectual, sendo autor de várias obras importantes para o estímulo da reflexão sobre o pensamento sistêmico na ciência.

[...] Pensador de uma cidadania terrestre que propõe uma ética de solidariedade, transita em diferentes contextos quer regionais, quer mundiais, de forma a contribuir para a construção do pensamento complexo (VEGA et al., 2001).

Entre os anos 1970 e 1971, o autor se dedicou à compreensão do pensamento sistêmico, da biologia e da cibernética para chegar a um projeto de reflexão sobre antropobiologia. Em 1973 publicou "Le Paradigme Perdu: la nature humaine", que nos convida a rever as categorias do humanismo; o homem biológico, social, cultural e religioso se torna um complexo. O respectivo livro foi o ponto de partida para a construção de "La Méthode", considerada sua obra mais completa e importante, que propõe a uma reforma do pensamento, sendo composta por seis volumes e traduzidas para diversas línguas: La Nature de la nature (1977); La Vie de la vie (1980); La Connaissance de la connaissance (1986), Les Idées: leur habitat, leur vie, leurs moeurs, leur organisation, (1995); L'Humanité de l'humanité, (2001) e Éthique (2004).

O método do pensamento sistêmico é a ativação de princípios anti-cartesianos e pós-cartesianos, no sentido de não rejeitar os resultados da ciência reducionista, mas descobrir a possibilidade de recusar suas limitações, no que concerne, a simplificação e mutilação dos saberes diante da complexidade dos problemas propostos.

\section{RESULTADOS E DISCUSSÃO}

No período de 1998 a 2002 foram defendidas 40 teses de livre-docência na ESALQ. Assim, foram analisadas todas as 40 teses, que totalizaram 5611 páginas, das quais duas $(5 \%)$, Teses $\mathrm{n}^{\circ} 34$ e $\mathrm{n}^{\circ} 38$, que somaram 278 páginas foram 
consideradas aliadas ao pensamento sistêmico por conter os sete aspectos do referido pensamento, conforme mencionado na Metodologia. As 38 teses restantes (95\%) estavam voltadas à fragmentação do conhecimento, ou seja, Teses $\mathrm{n}^{\circ} 1,2,3,4,5,6,7$, $8,9,10,11,12,13,14,15,16,17,18,19,20,21,22,23,24,25,26,27,28,29,30$, $31,32,33,35,36,37,39$ e 40.

Quanto à interdisciplinaridade, constatou-se presente em $3(7,5 \%)$ teses, Teses $\mathrm{n}^{\mathrm{o}} 15,34$ e 38 , pois os autores mencionam os grupos participantes da pesquisa, formados por pesquisadores de diversas áreas e também por pessoas externas à comunidade científica. Isso não foi verificado nas outras 37 teses (92,5\%).

$\mathrm{Na}$ Tese $\mathrm{n}^{\circ} 15$ estava registrado a colaboração de uma equipe interdisciplinar, entretanto, os problemas ambientais apresentados na pesquisa não foram tratados a partir da abordagem do pensamento sistêmico.

Quanto às abordagens das pesquisas das teses de livre-docência, algumas dificuldades foram encontradas, pois nem sempre nos textos estavam explícitas as questões ambientais, além dos títulos apresentarem uma linguagem científica bastante específica.

Os aspectos que envolvem o ser humano foram abordados principalmente nas teses, $\left(\mathrm{n}^{\mathrm{o}} 15,24\right.$ e 36), que apontaram o homem como causador dos problemas ambientais (por exemplo: como causador dos incêndios, erosão, desmatamento, etc). Uma vez relatadas as causas, foram justificados os meios para a restauração do ambiente. Ou seja, nas medidas propostas (reflorestamento de áreas urbanas e rurais, manejo de solo, etc) o homem local não foi considerado como agente das ações propostas. Dessa abordagem, emerge a questão: passado algum tempo esse ambiente continuará restaurado? Pode ser que sim, mas é mais provável que não, pois as teses não apresentaram dados, troca de informações, de saberes, estratégias e planejamentos que envolvessem a comunidade, o ser humano.

Nesse contexto cabe a tão famosa fórmula de Pascal insistentemente citada em várias obras de Morin:

Sendo todas as coisas causadas e causadoras, ajudadas e ajudantes, que interligam as mais distantes e as mais diferentes, considero impossível conhecer as partes sem conhecer o todo, assim como conhecer o todo sem conhecer particularmente as partes (MORIN, 2002a).

É importante chamar a atenção para a palavra particularmente, que não é sinônima de parcialmente, ou seja, o particular no texto citado refere-se à busca pelo essencial.

$\mathrm{Na}$ perspectiva a partir da qual as teses explicavam as causas dos processos observáveis na realidade, como o desmatamento, a erosão etc, não foram oferecidas alternativas que contassem com estratégias para reformular os valores, os saberes, os conhecimentos e os paradigmas científicos.

A partilha de saberes, por meio do envolvimento da comunidade, envolve uma série de aspectos como: culturais, sociais, econômicos, entre outros, que são 
interdependentes do contexto ambiental e são fundamentais para o entendimento da problemática ambiental.

É importante testar a viabilidade de alternativas de recuperação de fragmentos que apresentem um baixo custo de implantação, e se adéqüem às condições sócioeconômicas, culturais e ambientais locais [...] É fundamental envolver ao mínimo, os agricultores e trabalhadores rurais nas atividades de recuperação de cobertura florestal. Essas pessoas são profundos conhecedores da realidade local e têm interesses diferenciados com relação às florestas (VIANA, 2002).

Portanto, questionou-se na análise de conteúdo quais os objetivos das teses, a que se visava e quais os resultados alcançados em relação aos aspectos mencionados acima, uma vez que fazem parte do contexto do pensamento sistêmico e interdisciplinar. Esses aspectos não foram encontrados nas 38 teses, exceto nas teses $\mathrm{n}^{\mathrm{o}} 34$ e 38. O que ocorreu foram resultados de ações pontuais (reflorestamento, manejo do solo, plantio baseado em determinado modelo, a resistência de plantas daninhas aos herbicidas, etc) ocultando-se as inter-relações do processo como um todo. Logo, a questão ambiental acaba não sendo concebida como uma problemática de caráter eminentemente social, generalizada, de alcance planetário, mas sim fragmentada (LEFF, 2002).

Em outras palavras, durante a leitura das teses desenvolvidas pelos docentes da ESALQ, pode-se observar que a maioria foi elaborada com eficiência, do ponto de vista cartesiano, pois estão completamente desconectadas da realidade complexa.

Em síntese, as teses de livre-docência limitaram-se a levantar dados específicos, sendo incapazes de instigar o pensar sobre os problemas sociais e humanos envolvidos nas questões ambientais. Quando mencionado, o Social apareceu absorvido por visões biologistas; não se chegou à raiz dos problemas ambientais. A maioria dos problemas ambientais tem suas raízes em fatores sociais, econômicos e culturais e tornou-se visível que as pesquisas minimizaram ou reduziram a especificidade dos processos sociais em suas análises. Esse diagnóstico é bastante semelhante à observação de Leff:

Muitas pesquisas sobre mudanças ambientais minimizam ou reduzem a especificidade dos processos sociais em suas análises. A conexão entre o social e o natural limitou-se ao propósito de internalizar normas ecológicas e tecnológicas às teorias e às políticas econômicas, deixando à margem a análise do conflito social e o terreno estratégico do político que atravessam o campo ambiental (LEFF, 2002).

\section{CONCLUSÕES E CONSIDERAÇÕES FINAIS}

A pesquisa concluiu que:

- As teses de livre-docência seguiram linhas temáticas nas quais suas pesquisas não apresentaram em seus conteúdos uma análise ambiental com visão sistêmica ou complexa; 
- As pesquisas das teses de livre-docência da ESALQ não contemplaram uma dimensão ambiental em bases conceituais integradas e interdisciplinares, ocorrendo uma forte tendência à fragmentação cartesiana dos temas. Assim, a interdisciplinaridade na produção do conhecimento ainda representa, na produção científica analisada da ESALQ, um desafio a ser enfrentado, com obstáculos epistemológicos, metodológicos e institucionais.

Desse modo, concluiu-se que as pesquisas das teses de livre-docência da ESALQ, analisadas pelos indicadores empregados pelo estudo, encontram-se amplamente defasadas em relação à incorporação do pensamento sistêmico. Isso não significa, no entanto, que não existam pesquisadores da ESALQ que empreguem o pensamento sistêmico ou utilizem outros enfoques alternativos, diferentes dos tradicionais que partem de fundamentos diferentes aos da ciência clássica.

O pensamento sistêmico e seus desdobramentos são elementos fundamentais para o entendimento apropriado da realidade e as repercussões da ausência desse pensamento são difíceis de serem avaliadas, mas os danos têm enormes proporções, podendo afetar não apenas a capacidade crítica dos pesquisadores, mas também o ensino que a Instituição oferece a seus alunos.

Cabe ressaltar que se reconhece a existência de outros paradigmas e não se pretende com a presente pesquisa, afirmar que o paradigma do pensamento sistêmico seja o mais apropriado e que apresentará soluções para toda a problemática ambiental, principalmente por meio da educação. Outrossim, ele é um importante instrumento auxiliar na compreensão do pensamento ainda hegemônico, como esclarece Morin no texto a seguir:

Trata-se de entender o pensamento que separa e que reduz, no lugar do pensamento que distingue e une. Não se trata de abandonar o conhecimento das partes pelo conhecimento das totalidades, nem da análise pela síntese; é preciso conjugá-las (MORIN, 2002b).

Aponta-se, ainda, como limitação do estudo, o emprego das teses de livredocência como parâmetros de análise da produção científica da Instituição, dado que essa produção vai muito, além das teses. No entanto, vale ressaltar que essas podem ser tomadas como indicadores importantes da produção hegemônica, pois são pesquisas profundamente vinculadas à Instituição.

Enfim, espera-se que este estudo, na medida do possível, venha a fornecer subsídios à reflexão para os pesquisadores da ESALQ e demais membros da Instituição e da comunidade científica em geral. 


\section{AGRADECIMENTOS}

A autora agradece ao Prof. Dr. Antônio Ribeiro de Almeida Júnior, do Departamento de Economia, Sociologia e Administração da ESALQ/USP, a orientação durante o mestrado.

A CAPES pela concessão de bolsa de mestrado.

\section{REFERÊNCIAS}

BACHELARD, G. A formação do espírito científico. $2^{\mathrm{a}}$ Ed. Rio de Janeiro: Contraponto, 1999.

GARVEY, W.D. Communication: the essence of science. Oxford: Pergamon, 1979.

KUHN, T.S. A estrutura das revoluções científicas. $5^{\text {a }}$ Ed. São Paulo: Perspectiva, 2000.

LEFF, E. Epistemologia ambiental. 2 $2^{\mathrm{a}}$ Ed. São Paulo: Cortez, 2002.

MASSARINI, L; MOREIRA, I.C. A retórica e a ciência dos artigos originais à divulgação científica. Revista Ciência \& Ambiente, v.1, p.31-47, 1990.

MEADOWS, A.J. A comunicação científica. Brasília: Briquet de Lemos/Livros, 1999.

MORIN, E. Le Paradigme Perdu: La Nature Humane. Paris, Seuil, 1973.

MORIN, E. La Méthode I - La Nature de La Nature. Paris, Seuil, 1977.

MORIN, E.Ciência com Consciência. Rio de Janeiro: Bertrand. Brasil, 1996.

MORIN, E. La Méthode II - La Vie de La Vie. Paris, Seuil, 1980.

MORIN, E. La Méthode III - La Connaissance de La Connaissance. Paris, Seuil, 1986.

MORIN, E. La Méthode IV - Les Idées: Leur Habitat, Leur Vie, Leurs Moeurs, Leur Organization. Paris, Seuil, 1995.

MORIN, E. La Méthode V - l'humanitéde l'humanité. Paris, Seuil, 2001. 
MORIN, E. La Méthode VI - Éthique. Paris, Seuil, 2004.

MORIN, E. Notas para um "Emílio" contemporâneo. In: VEGA, A.P.; ALMEIDA, C.R.S.PETRAGLIA, I. (Org.). Edgar Morin: Ética cultura e educação. São Paulo: Cortez, 2001. p.149-155.

MORIN, E. A cabeça bem-feita. 7. Ed. Rio de Janeiro: Bertrand Brasil, 2002a.

MORIN, E. Os setes saberes necessários à educação do futuro. $5^{\mathrm{a}} \mathrm{Ed}$. Brasília: Cortez, 2002b.

MORIN, E.; KERN, A.B. Terra-Pátria. $3^{\text {a }}$ Edição. Porto Alegre: Editora Sulina, 2002.

NOJIMOTO, T. A pesquisa experimental agrícola universitária paulista: uma análise crítica e metodológica a partir das teses de livre-docência. 1996. 322f. Tese (Livre-Docência) - Faculdade de Ciências Agronômicas, Universidade Estadual Paulista "Júlio de Mesquita", Botucatu. 1996.

VEGA, A.P.; ALMEIDA, C.R.S.; PETRAGLIA, I. Edgar Morin: Ética, Cultura e Educação. São Paulo: Cortez, 2001.

VIANA, V.M. As florestas brasileiras e os desafios do desenvolvimento sustentável: manejo, certificação e políticas públicas apropriadas. 2002. 163f. Tese (Livre-Docência) - Escola Superior de Agricultura "Luiz de Queiroz", Universidade de São Paulo, Piracicaba. 2002. 